\title{
Corticosteroid and progesterone transactivation of mineralocorticoid receptors from Amur sturgeon and tropical gar
}

\author{
Akira Sugimoto $^{1}$, Kaori Oka ${ }^{1}$, Rui Sato ${ }^{1}$, Shinji Adachi ${ }^{2}$,
} Michael E. Baker ${ }^{3, *}$, Yoshinao Katsu ${ }^{1,4, *}$

${ }^{1}$ Graduate School of Life Science, Hokkaido University, Sapporo, Japan; ${ }^{2}$ Faculty of Fisheries Sciences, Hokkaido University, Hakodate, Japan; ${ }^{3}$ Department of Medicine, University of California, San Diego, CA, USA; ${ }^{4}$ Department of Biological Sciences, Hokkaido University, Sapporo, Japan

\section{*Corresponding authors:}

Michael E. Baker: mbaker@ucsd.edu

Yoshinao Katsu; ykatsu@sci.hokudai.ac.jp

\section{Abstract}

The response to a panel of steroids by the mineralocorticoid receptor (MR) from Amur sturgeon and tropical gar, two basal ray-finned fish, expressed in HEK293 cells was investigated.

Half-maximal responses (EC50s) for transcriptional activation of sturgeon MR by 11-deoxycorticosterone, corticosterone, 11-deoxycortisol, cortisol and aldosterone, and progesterone were between $13 \mathrm{pM}$ and $150 \mathrm{pM}$. For gar MR, EC50s were between $8 \mathrm{pM}$ and 55 pM. Such low EC50s support physiological regulation by these steroids of the MR in sturgeon and gar. Companion studies with human MR and zebrafish MR found higher EC50s compared to EC50s for sturgeon and gar MR, with EC50s for zebrafish MR closer to gar and sturgeon MR than was human MR. For zebrafish MR, EC50s were between $75 \mathrm{pM}$ and $740 \mathrm{pM}$; for human MR, EC50s were between $65 \mathrm{pM}$ and $2 \mathrm{nM}$. In addition to progesterone, spironolactone and 19nor-progesterone were agonists for all three fish MRs, in contrast to their antagonist activity for human MR, which is hypothesized to involve serine-810 in human MR because all three steroids are agonists for a mutant human Ser810Leu-MR. Paradoxically, sturgeon, gar and zebrafish MRs contain a serine corresponding to serine- 810 in human MR. Our data suggests alternative mechanism(s) for progesterone, spironolactone and 19nor-progesterone as MR agonists in these three ray-finned fishes and the need for caution in applying data for progesterone signaling in zebrafish to human physiology. 


\section{INTRODUCTION}

The mineralocorticoid receptor (MR) is a transcription factor that belongs to the nuclear receptor family, a diverse group of transcription factors that also includes receptors for androgens (AR), estrogens (ER), glucocorticoids (GR) and progestins (PR), and other small lipophilic ligands, such as thyroid hormone and retinoids [1-5]. The MR and GR are descended from a common corticosteroid receptor (CR), which are present in lampreys and hagfish [5-7]. Several corticosteroids (Figure 1), including aldosterone (Aldo), cortisol (F), 11-deoxycortisol (S), corticosterone (B) and 11-deoxycorticosterone (DOC), as well as progesterone (Prog), are transcriptional activators of Atlantic sea lamprey CR and hagfish CR [6]. Among these steroids, Aldo, the main physiological activator of the MR in human and other terrestrial vertebrates [8-11], had the lowest half-maximal response (EC50) for transcriptional activation of the CR. This strong response to Aldo is surprising because Aldo is not found in either lamprey or hagfish serum [6]. S, which along with DOC is present in Atlantic sea lamprey serum, has been found to have mineralocorticoid activity in lamprey $[12,13]$.

Distinct MR and GR genes first appear in cartilaginous fishes (Chondrichthyes), such as sharks, rays and skates [6, 14]. Carroll et al. [14] determined EC50s of several corticosteroids for skate MR; EC50s were $70 \mathrm{pM}$ for Aldo, $30 \mathrm{pM}$ for DOC, $90 \mathrm{pM}$ for $\mathrm{B}, 1 \mathrm{nM}$ for $\mathrm{F}$ and $22 \mathrm{nM}$ for $\mathrm{S}$. In teleosts, which comprise about $95 \%$ of known ray-fish species (Actinopterygii), corticosteroid activation of the MR has been investigated for cichlid [15], trout [16], carp [17], midshipman fish [18] and zebrafish [19], with Aldo, F and DOC being the principal steroids that were studied. Although Aldo has not been found in teleost fish [20], Aldo has a low EC50 for teleost MRs, similar to that found for Aldo activation of lamprey CR and skate MR. DOC also has a low EC50 for teleost MRs, and DOC has been proposed as mineralocorticoid in fish [16, 21-25]. F also has been proposed to be ligand for teleost fish MR [22, 24, 25]. The response of the teleost MRs to B and S, which are found in fish [25, 26], has been studied only in trout, in which the EC50s are $10 \mathrm{nM}$ for B and $3.7 \mathrm{nM}$ for S [16]. Interestingly, spironolactone (spiron) and Prog are agonists for trout MR [16], in contrast to their antagonist activity for human MR [16,27]. Spiron also is an agonist for zebrafish MR [19]. Together, these studies indicate that several corticosteroid(s) are potential transcriptional activators of teleost MRs [22, 25, 28, 29].

An important gap in our understanding of the evolution of selectivity of ray-finned fish MRs for steroids is the absence of data on the MR in Chondrostei (sturgeons, paddlefishes, reedfishes, bichirs) and Holostei (bowfins, gars), which evolved before a fish-specific genome duplication occurred after the split of the 
1 Acipenseriformes (sturgeons) and the Semionotiformes (gars) from the lineage leading

2 to teleost fish, but before the divergence of Osteoglossomorpha (Figure 2) [30-32].<smiles>C[C@@]12C[C@@H](C(O)CCC1C(=O)CO)C1C2CCC2=CC(=O)CC[C@@]21C</smiles>

Aldosterone [Aldo]

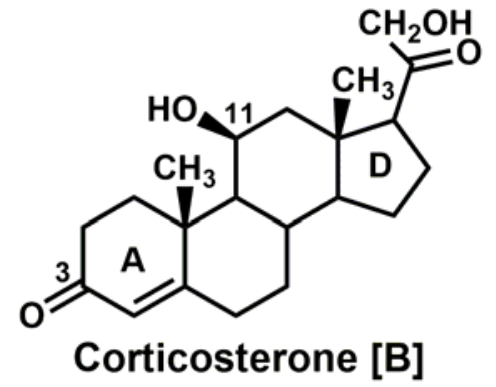

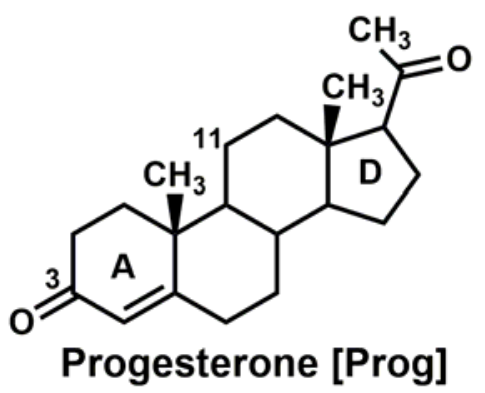<smiles>CC(=O)[C@]1(O)CCC2C3CCC4=CC(=O)CC[C@]4(C)[C@H]3[C@@H](O)C[C@]21C</smiles>

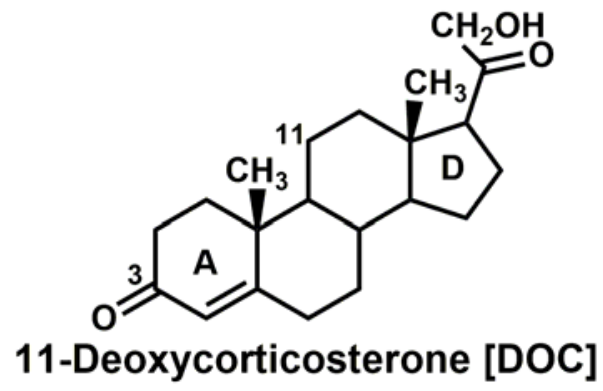

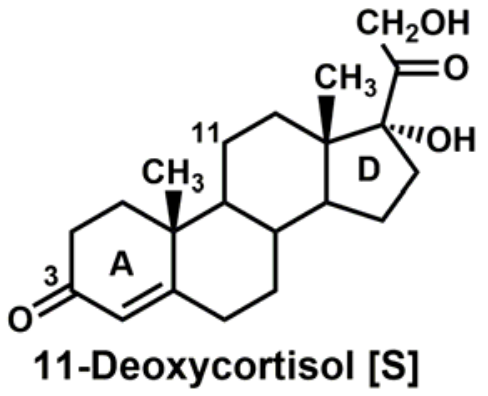

6 Figure 1. Structures of potential steroid regulators of fish MR.

7 Aldo, the physiological ligand for terrestrial vertebrate MRs, is not found in fish [20]. F and

8 DOC have been proposed to be mineralocorticoids in teleosts $[22,25] . \quad \mathrm{S}$ is a ligand for

9 corticosteroid receptor in lamprey [12]. Progesterone is an antagonist for human MR [27]. 


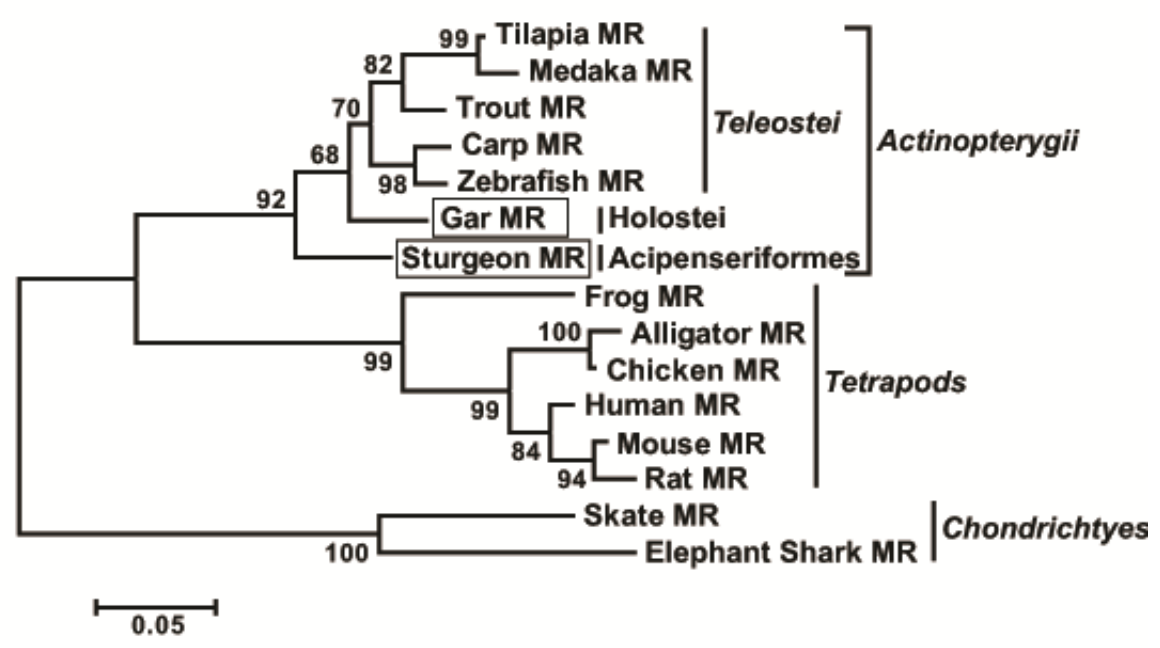

2 Figure 2. Phylogenetic relationship of sturgeon and gar MRs to other vertebrates.

3 To investigate the relationship of sturgeon and gar to other fish, we constructed a phylogenetic

4 tree of the steroid-binding domains on MRs in sturgeon, gar, selected teleosts, elasmobranchs

5 and tetrapods. The phylogenetic tree was constructed using the maximum likelihood with

6 JTT+G model with 1000 bootstrap replications, which are shown as percentages at the nodes of

7 the tree.

Our interest in the evolution of steroid hormone action $[4,5,33,34]$ prompted us to investigate transcriptional activation of the MR from Amur sturgeon, Acipenser schrenckii, and tropical gar, Atractosteus tropicus by a broad panel of corticosteroids (Aldo, F, B, DOC, S), Prog, spiron and 19nor-progesterone (19norP), a steroid that has not previously been studied for activation of fish MR. To gain further insight into the evolution of steroid specificity, we compared our results with companion studies of zebrafish and human MRs. In agreement with studies of teleost MRs, we find that Aldo and DOC have the lowest EC50 (highest activity) for sturgeon and gar MRs. However, we also find that S, B, F, and Prog have low EC50s, consistent with these steroids also having a physiological role as ligands for these MRs. Spiron and 19norP also activated sturgeon and gar MRs. In comparison, zebrafish MR has a strong response to Aldo and DOC and a good response to B, F, S Prog, spiron and 19norP, while human MR has strong response to Aldo, DOC and B and a good response to F and S, and a weak response to Prog and 19norP and no response to spiron. The weak response to Prog and 19norP and absence of a response to spiron by human MR is in agreement with other studies [27, 35, 36]. The strong response to 19 norP, Prog and spiron of sturgeon, gar and zebrafish MR is perplexing because the basis for the low response to to these steroids by human MR is thought to be due to the presence of Ser-810 on $\alpha$-helix 5 [27, 37, 38]. 
1 human MR with Ser810Leu mutation [27, 37, 38]. Sturgeon, gar and zebrafish MRs contain a

2 serine corresponding to serine- 810 in human MR, suggesting the presence of an alternative

3 mechanism for these steroids acting as MR agonists in these three ray-finned fishes, as well as

4 the need to apply caution in interpreting data on Prog activity in zebrafish to human physiology.

\section{MATERIALS AND METHODS}

\section{Animals and chemical reagents}

Amur sturgeon and tropical gar were obtained as described previously [32]. All

experimental procedures involving live fish followed the policies and guidelines of the Hokkaido

University Animal Care and Use Committee. Aldosterone (Aldo) (CAS 52-39-1),

corticosterone (B) (CAS 50-22-6), cortisol (F) (CAS 50-23-7), 11-deoxycortisol (S) (CAS

152-58-9), 11-deoxycorticosterone (DOC) (CAS 64-85-7), progesterone (Prog) (CAS 57-83-0),

19nor-progesterone (19norP) (CAS 472-54-8), spironolactone (Spiron) (CAS 52-01-7),

5 $\alpha$-dihydrotestosterone (DHT) (CAS 521-18-6), and 17ß-estradiol (E2) (CAS 50-28-2) were

purchased from Sigma-Aldrich. For the reporter gene assays, all hormones were dissolved in dimethyl-sulfoxide (DMSO) and the final concentration of DMSO in the culture medium did not exceed $0.1 \%$.

\section{Molecular cloning of mineralocorticoid receptors}

Two conserved amino acid regions, GCHYGV and LYFAPD of vertebrate MRs were selected and degenerate oligonucleotides were used as primers for PCR. First-strand cDNA was synthesized from $2 \mu \mathrm{g}$ of total RNA isolated from the liver after amplification, and an additional primer set (CKVFFK and LYFAPD) was used for the second PCR. The amplified DNA fragments were subcloned with TA-cloning plasmid pGEM-T Easy vector, sequenced using a BigDye terminator Cycle Sequencing-kit with T7 and SP6 primers, and analyzed on the 3130

\section{Database and sequence analysis}

MRs for phylogenetic analysis were collected with Blast searches of GenBank. A 


\section{Construction of plasmid vectors}

DNA polymerase. PCR products were gel-purified and ligated into pcDNA3.1 vector. Mouse PCR, and inserted into pGL3-basic vector containing the Photinus pyralis lucifease gene. All constructs were verified by sequencing.

\section{Transactivation Assay}

Human embryonic kidney 293 (HEK293) cells were used in the reporter gene assay.

Transfection and reporter assays were carried out as described previously [33], except that we used PEI-max as transfection reagent [43]. All transfections were performed at least three times, employing triplicate sample points in each experiment. The values shown are mean \pm SEM from three separate experiments, and dose-response data and EC50 were analyzed using GraphPad Prism.

\section{Statistical methods}

\section{RESULTS}

\section{Isolation of mineralocorticoid receptors from sturgeon and gar}

We cloned sturgeon MR cDNA containing an open reading frame encoding 953 amino acids (GenBank accession LC149818)], and gar MR cDNA containing an open reading frame encoding 987 amino acids (GenBank accession LC149819). Sturgeon and gar MR sequences

\section{Phylogenetic analysis of ancient fish corticoid receptors}

To investigate the evolutionary position of gar and sturgeon MR in relationship to other 
1 shark and selected terrestrial vertebrates. Consistent with the evolution of Acipenseriformes

2 and Holostei, phylogenetic analysis places sturgeon and gar MRs close to the base of ray-finned

3 fish (Figure 2).

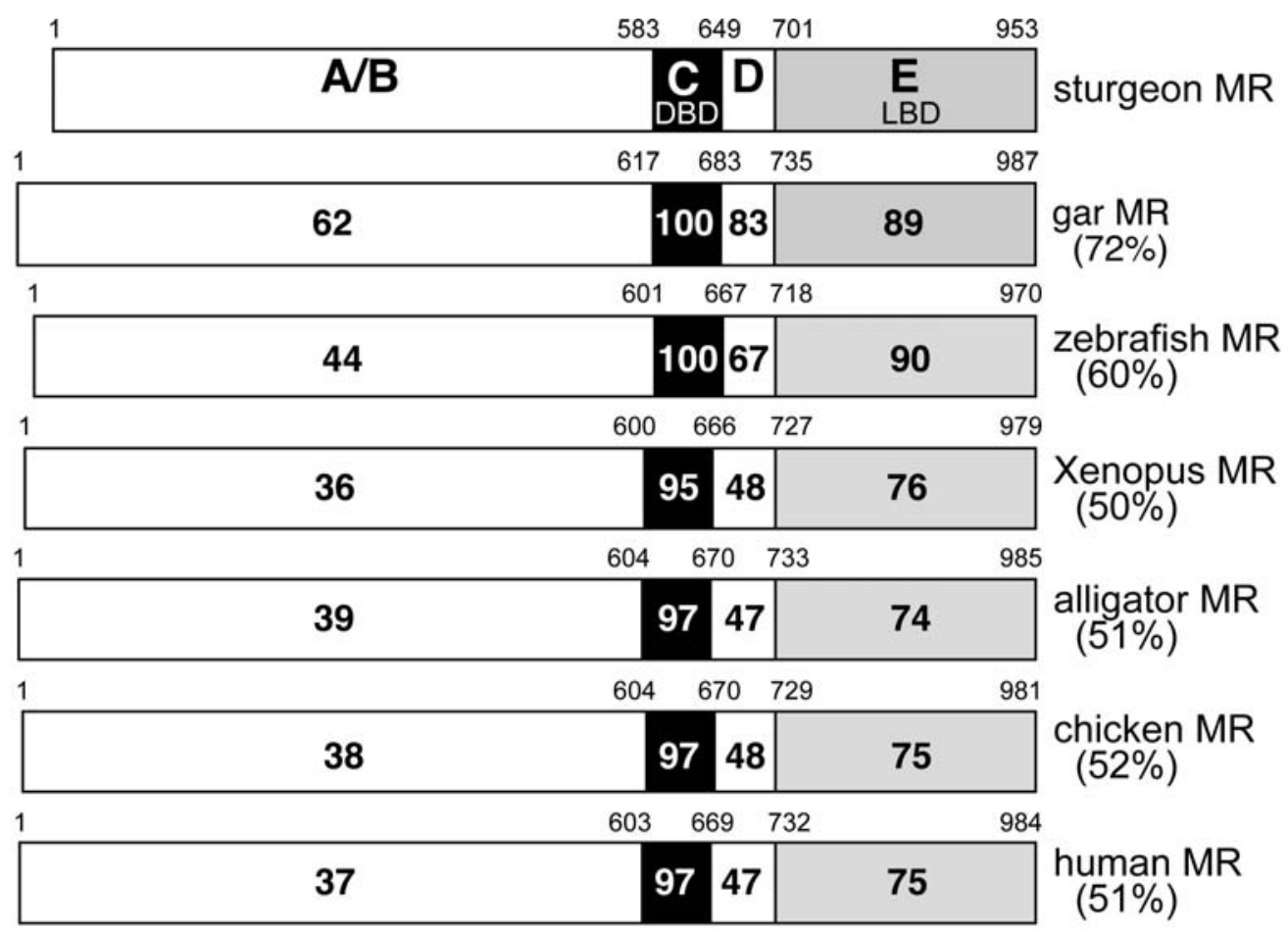

5

6 Figure 3. Comparisons of functional domains in sturgeon, gar, zebrafish, $X$. laevis, alligator,

7 chicken and human MRs.

8 Comparison of the domains in sturgeon MR gar, zebrafish, X. laevis, alligator, and human MR

9 MR. The functional A/B domain, C domain, D domain and E domain are schematically

10 represented with the numbers of amino acid residues at each domain boundary indicated. The

11 percentage of amino acid identity between domains is depicted. GenBank accession numbers

12 are: LC149818 for sturgeon MR; LC149819 for gar MR; NM_001100403 for zebrafish MR;

13 NM_001090605 for Xenopus MR; AB701406 for alligator MR; and NM_000901 for human MR.

\section{Strong response to 3-keto-steroids by sturgeon and gar mineralocorticoid receptors}

We examined steroid-inducible transcriptional activation of gar and sturgeon MRs using the MMTV-driven reporter construct [33,44]. For comparison, we also examined transcriptional activation of human MR and zebrafish MR. At $1 \mathrm{nM}, \mathrm{Aldo}, \mathrm{B}, \mathrm{S}, \mathrm{DOC}, \mathrm{F}$ and

20 Prog were strong inducers of luciferase activation by gar MR and sturgeon MR and by zebrafish 
1 MR, with the exception of Prog which had a lower signal. These MRs show little stimulation

2 by $1 \mathrm{nM}$ DHT and E2 (Figure 4). At $1 \mathrm{nM}$, Aldo, B, DOC were strong transcriptional activators

3 of human MR, which was activated to a lesser extent by S, and weakly activated by Prog (Figure

$44)$.
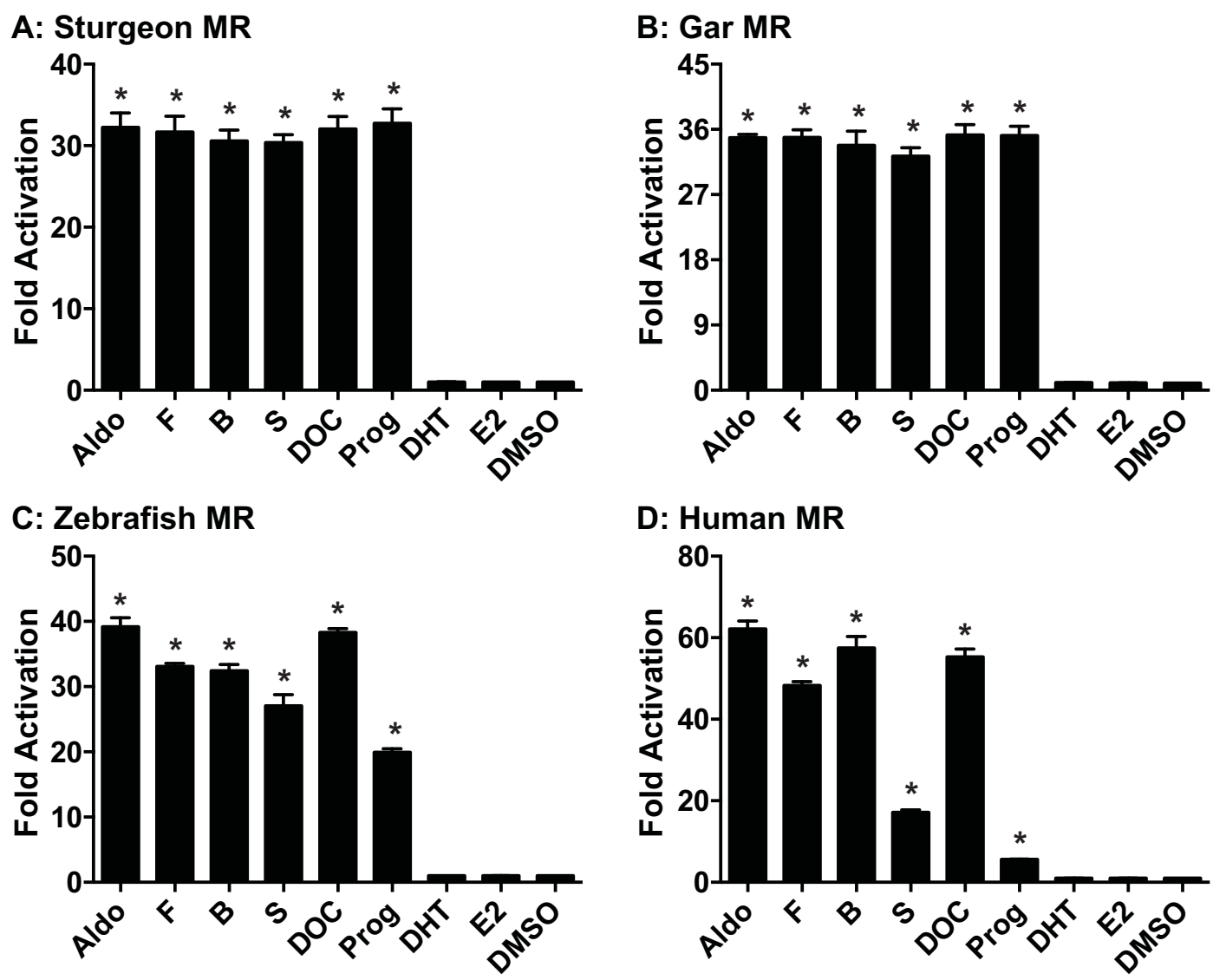

\section{Steroid Concentration $=1 \mathrm{nM}$}

7 Figure 4. Ligand-specificities of fish and human MRs.

8 Full-length sturgeon MR (A), gar MR (B), zebrafish (C), and human MR (D) were expressed in

9 HEK293 cells with an MMTV-luciferase reporter. Cells were treated with $10^{-8} \mathrm{M}$ Aldo, F, B, S,

10 DOC, Prog, 5 $\alpha$-dihydrotestosterone (DHT), 17 $\beta$-estradiol (E2) or vehicle alone (DMSO).

11 Results are expressed as means \pm SEM, $n=3$. Y-axis indicates fold-activation compared to the

12 activity of control vector with vehicle (DMSO) alone as 1. and the evidence that spiron is an agonist for trout [16] and zebrafish MRs [19] stimulated us to examine transcriptional activation of sturgeon and gar MRs by spiron, an agonist for human MR. We also investigated transcriptional of sturgeon, gar and zebrafish MRs by 19norP, which, like 
1 and 19norP are agonists for sturgeon, gar and zebrafish MRs.

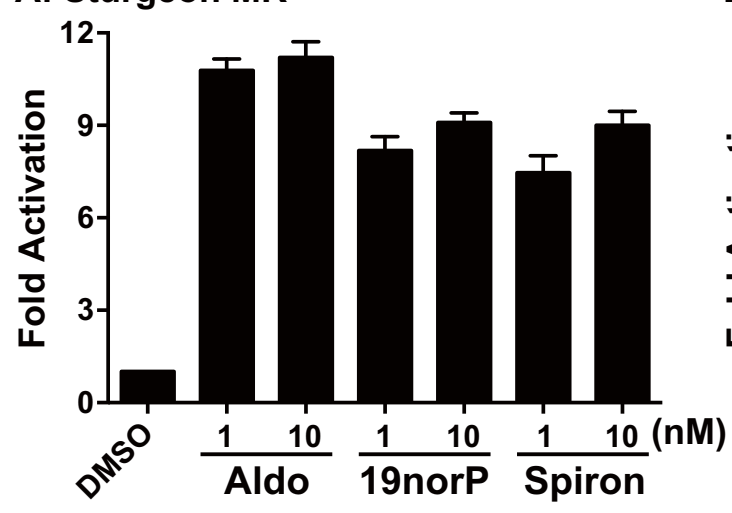

\section{A: Sturgeon MR}

B: Gar MR

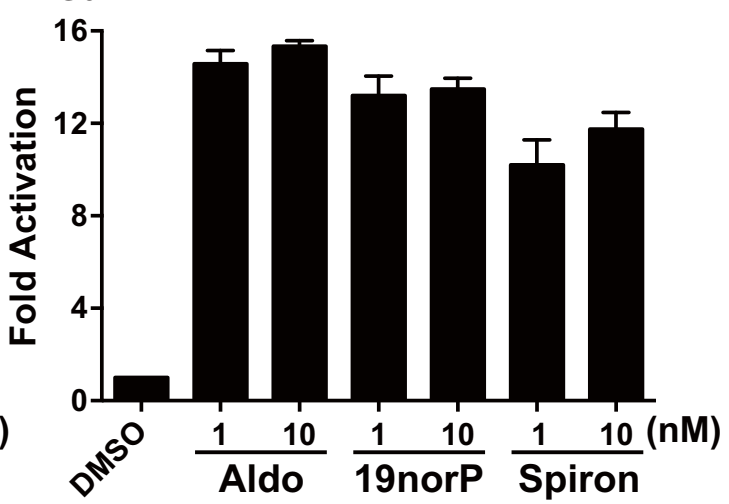

D: Human MR

C: Zebrafish MR
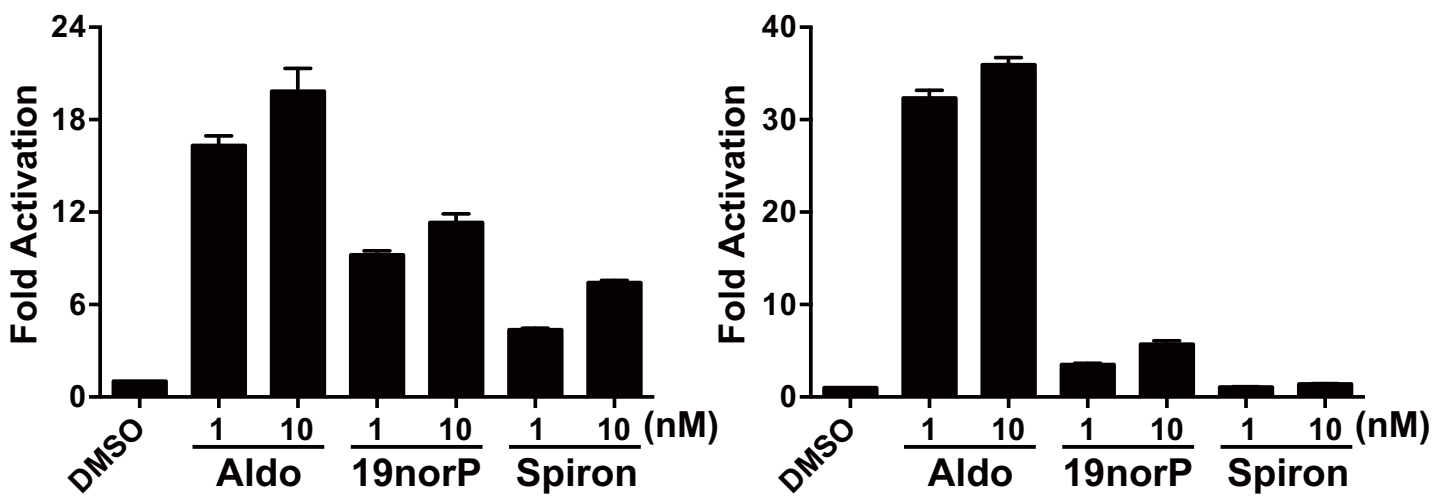

4

5 Figure 5. Transcriptional activation by 19nor-progesterone and spironolactone of sturgeon,

6 gar, zebrafish and human MRs.

7 Full-length sturgeon MR (A), gar MR (B), zebrafish MR (C), and human MR (D) were

8 expressed in HEK293 cells with an MMTV-luciferase reporter. Cells were treated with $1 \mathrm{nM}$ or

$910 \mathrm{nM}$ Aldo, 19norP or spiron or vehicle alone (DMSO). Results are expressed as means \pm

10 SEM, N=3 and represent fold-activation compared to the control vector with vehicle.

11

13 human MRs by Aldo, F, B, DOC, S and Prog (Figure 6, Table 1). Both gar and sturgeon MRs

14 had similar low EC50s, which varied from $7.7 \mathrm{pM}$ to $150 \mathrm{pM}$ for these steroids. For each

15 steroid, the EC50s for gar MR were a little lower than for sturgeon MR. 
A: Sturgeon MR (Aldo, B, S)

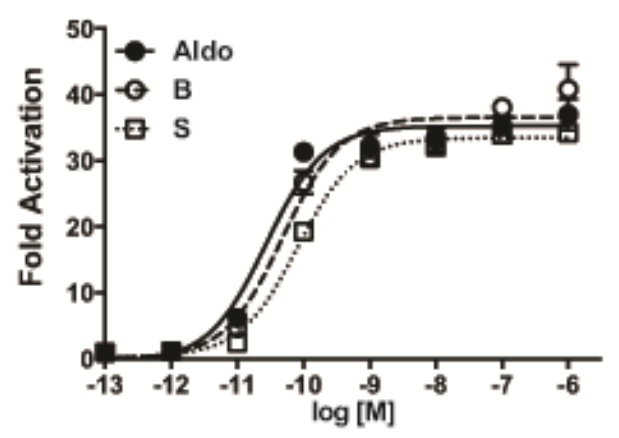

C: Gar MR (Aldo, B, S)

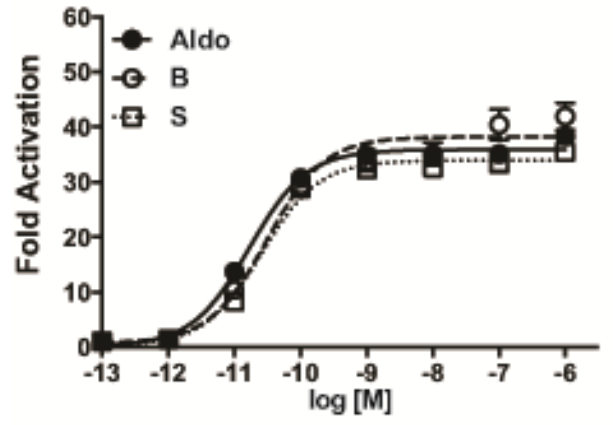

E: Zebrafish MR (Aldo, B, S)

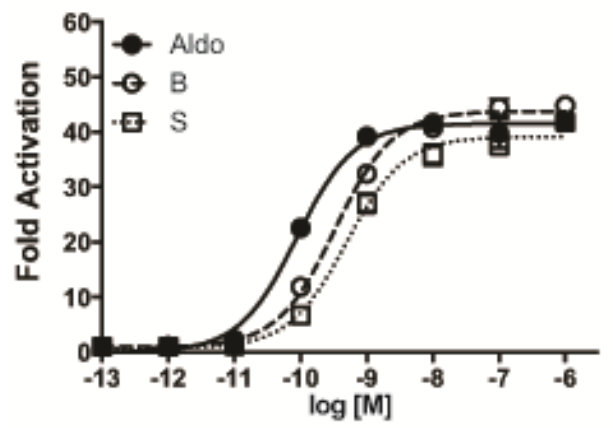

G: Human MR (Aldo, B, S)

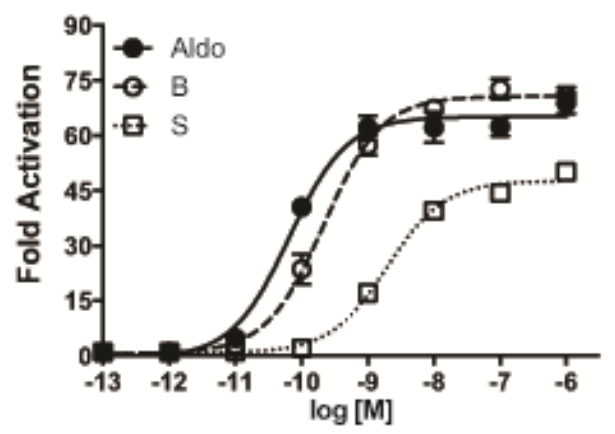

B: Sturgeon MR (Prog, F, DOC)

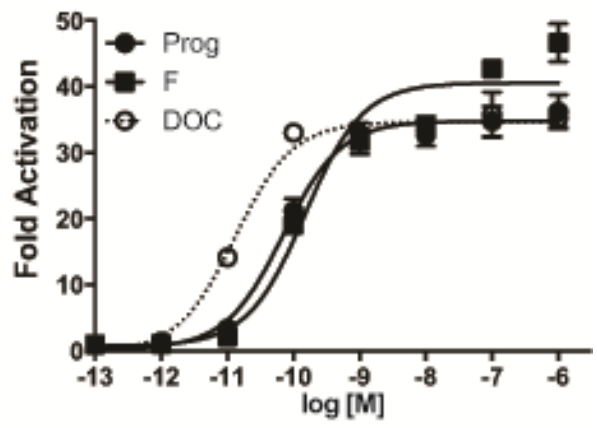

D: Gar MR (Prog, F, DOC)

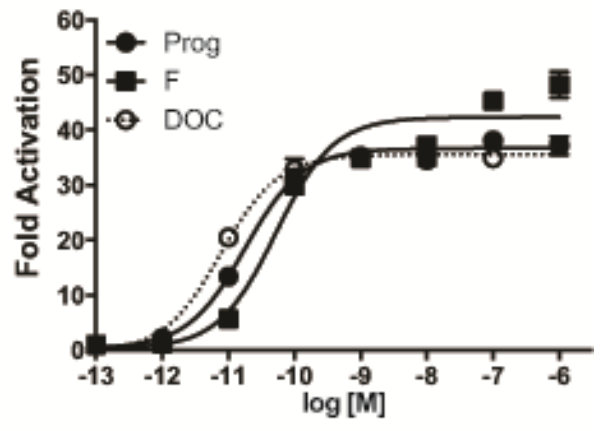

F: Zebrafish MR (Prog, F, DOC)

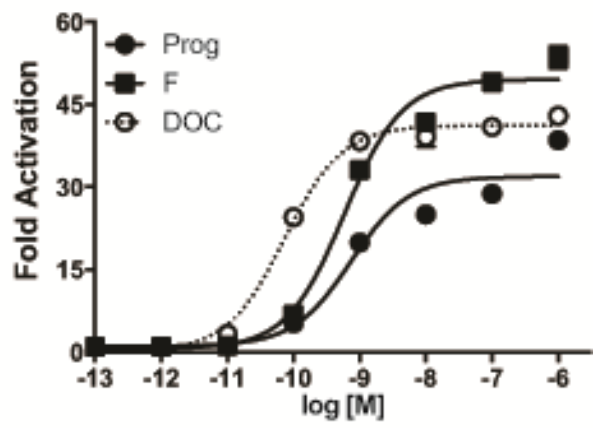

H: Human MR (Prog, F, DOC)

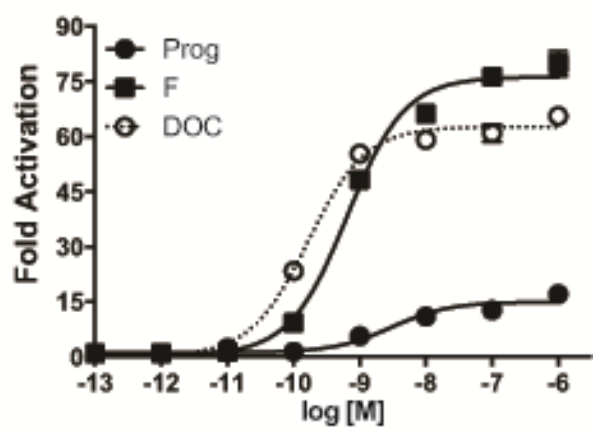

2 Figure 6. Concentration-dependent transcriptional activities of fish and human MRs.

3 Concentration-response profiles of full-length sturgeon MR (A and B), gar MR (C and D),

4 zebrafish MR (E and F), and human MR ( $G$ and $H)$ for various steroids. HEK293 cells were

5 transiently transfected with the MMTV-containing vector together with an MR expression vector.

6 Cells were incubated with increasing concentrations of Aldo, B, and S (A, C, E, and G) or Prog, 
1 F, and DOC (B, D, F, and H) $\left(10^{-13}\right.$ to $\left.10^{-6} \mathrm{M}\right)$. Data are expressed as a ration of steroid to

2 vehicle (DMSO). Each column represents the mean of triplicate determinations, and vertical

3 bars represent the mean \pm SEM.

4

Table 1. EC50 activities for 3-keto-steroid transcriptional activation of sturgeon, gar,

zebrafish and human MRs

\begin{tabular}{|c|c|c|c|c|c|c|}
\hline & Aldo & DOC & B & $\mathbf{S}$ & $\mathbf{F}$ & Prog \\
\hline Sturgeon MR & $2.7 \times 10^{-11}$ & $1.3 \times 10^{-11}$ & $4.8 \times 10^{-11}$ & $8.2 \times 10^{-11}$ & $1.5 \times 10^{-10}$ & $7.0 \times 10^{-11}$ \\
\hline Gar MR & $1.7 \times 10^{-11}$ & $7.7 \times 10^{-12}$ & $3.1 \times 10^{-11}$ & $2.6 \times 10^{-11}$ & $5.3 \times 10^{11}$ & $1.8 \times 10^{-11}$ \\
\hline Zebrafish MR & $8.8 \times 10^{-11}$ & $7.4 \times 10^{-11}$ & $3.3 \times 10^{-10}$ & $5.0 \times 10^{-10}$ & $5.9 \times 10^{-10}$ & $7.4 \times 10^{-10}$ \\
\hline Human MR & $6.5 \times 10^{-11}$ & $1.7 \times 10^{-10}$ & $2.2 \times 10^{-10}$ & $2.0 \times 10^{-9}$ & $6.5 \times 10^{-10}$ & - \\
\hline
\end{tabular}

In comparison, EC50s of Aldo, B and F were similar for zebrafish and human MR and a little higher than their EC50s for sturgeon and gar MR. EC50s of DOC, S and Prog for zebrafish MR were higher than their EC50s for sturgeon and gar MR, but lower than the EC50s

12 for human MR. Prog had a lower, but still significant, maximal activation for zebrafish MR

13 while $100 \mathrm{nM}$ Prog had little activation of human MR. Overall all corticosteroids and Prog had

14 EC50s that would be consistent with a physiological role in transcription of the MR in sturgeon,

15 gar and zebrafish (Table 1, Figure 6).

In human MR, Ser-810 and Ala-773 are important in the low transcriptional activity of

17 Prog. Prog, spiron and 19norP can activate human MR with selective mutations at either

18 Ser-810 or Ala-773 [27, 37, 38]. For example, at $1 \mathrm{nM}$, prog, spiron and 19norP are agonist for

19 a Ser810Leu mutant MR [27, 37, 38]. We extracted the sequence of helices 3-5, which contain

20 Ser-810 and Ala-773, from sturgeon, gar and zebrafish MR (Figure 7) and other teleosts. All of

21 these ray-finned fish contain a serine and alanine that aligns with Ser-810 and Ala-773 in human 22 MR.
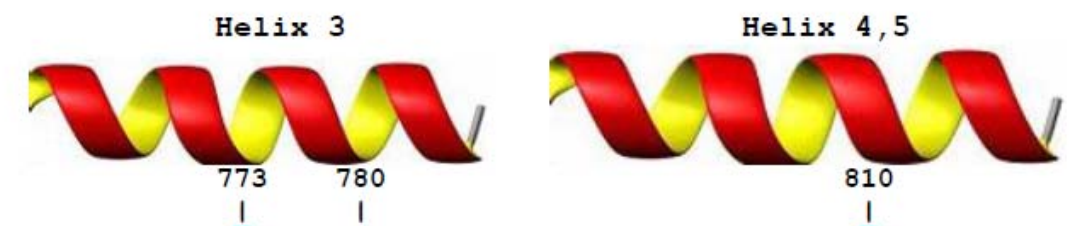

Human MR Chicken MR Frog MR Coelacanth MR zebrafish MR Gar MR Sturgeon MR skate MR Fleph Shark Lamprey CR 217 Hagfish CR

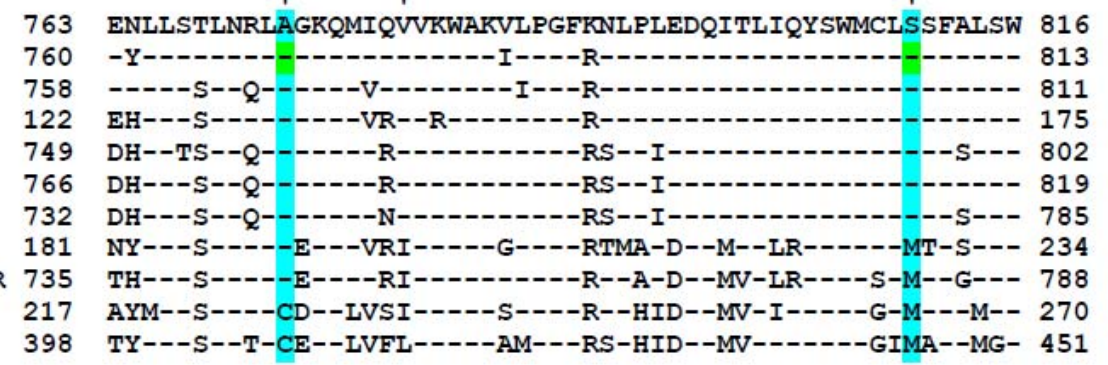




\section{1 human MR.}

2 Human Ser-810 and Ala-773 are conserved in ray-finned fish MRs. Skate MR, elephant shark

3 MR, lamprey CR and hagfish CR contain a methionine corresponding to human Ser-810.

4 Lamprey CR and hagfish CR contain a cysteine corresponding to Ala-773 in human MR.

5 Amino acids that are identical to amino acids in human MR are denoted by (-).

\section{DISCUSSION}

Several corticosteroids are physiological activators of the MR in cartilaginous fishes, ray-finned fishes and tetrapods. Interestingly, Aldo, the mineralocorticoid for terrestrial vertebrates, first appears in lungfish [45]. Nevertheless, Aldo is a potent activator of the lamprey CR [6], which is ancestral to the MR [5-7, 11]. Interestingly, F, DOC, B and S and Prog also are transcriptional activators of the CR in lamprey and hagfish [6], with only S, thus far, found to have mineralocorticoid activity in lamprey $[12,13]$. In skate, which has separate MR and GR genes, Aldo, F, DOC and B are strong transcriptional activators of the MR [14]. F, DOC, B, S and Prog are found in teleosts [26] and F and DOC have been proposed to be transcriptional activators of teleost MRs [4, 15-19, 21, 22, 24, 25].

Absent, until now, was information about the response to corticosteroids of MRs in sturgeon and gar, two basal fish that fill in the gap between elasmobranchs and teleosts (Figure 2). Here we report that sturgeon MR and gar MR have EC50s below $1 \mathrm{nM}$ for Aldo, F, DOC, B, S and Prog. Interestingly, we find that zebrafish MR also has a similar strong response to these corticosteroids and Prog. Moreover, spiron and 19norP are agonists for sturgeon, gar and zebrafish MRs. This low selectivity for 3-keto-steroids (Figure 1) that can activate these fish MRs resembles the response to these steroids by lamprey and hagfish CR [6] and skate MR [14]. Thus, this strong response of the MR to a broad panel of 3-keto-steroids was conserved after the third whole-genome duplication at the base of the teleosts [30-32, 46].

In contrast, human MR is more selective for 3-keto-steroids with higher EC50s for S and

Prog. Our data showing weak activation by Prog and 19norP of human MR is in agreement with other studies [35-37]. The strong response to Prog, spiron and 19norP of ray-finned fish MR is interesting in the light of the report by Geller et al. [27] that human MR with a Ser810Leu mutation was activated by $1 \mathrm{nM}$ Prog, 19norP and spiron. Mutagenesis studies and structural analyses of the MR-Leu810 mutant led to the hypothesis that Leu-810 on $\alpha$-helix 5 has stabilizing van der Waals contacts with Ala-773 on $\alpha$-helix 3 [27, 37, 38] to explain the strong transcriptional activation by Prog, 19norP and spiron. This serine and alanine are conserved in and sturgeon and gar MRs, as well as in zebrafish MR (Figure 7) [4] and other teleost MRs indicating that other mechanism(s) can lead to a strong response of sturgeon, gar and zebrafish 
1 zebrafish is an established model system for studying gene regulation in teleosts, as well as

2 providing insights into human physiology [47]. Prog activation of zebrafish MR may confound

3 data that focuses on activation of the PR. Prog may also be an agonist for the MR in medaka

4 and other teleosts that have a serine and alanine that correspond to Ser-810 and Ala-773 in

5 human MR.

\section{Mechanisms for regulation of steroid activation of ray-finned fish MR}

The strong response of zebrafish MR, as well as sturgeon and gar MRs, to five

corticosteroids, Prog, 19norP and spiron requires one or more mechanisms to provide

steroid-specific regulation of transcriptional activation of these ray-finned fish MRs. At this

time, such mechanisms in gar, sturgeon and zebrafish MRs or other ray fined fish MRs are

poorly understood. Clues for possible mechanisms may be found from insights into regulation

cells for regulating access of $\mathrm{F}$ and $\mathrm{B}$ to mammalian MR by tissue specific expression of

\section{Authors Contributions}

A.S., K.O., R.S., and S.A. carried out the research. M.E.B. and Y.K. conceived and designed the experiments and wrote the paper. All authors gave final approval for

32 publication. We have no competing interests.

\section{Acknowledgments}

35 We thank colleagues in our laboratories. We also thank Drs. Arlette Hernandez-Franyutti and 


\section{Funding}

3 K.O. was supported by the Japan Society for the Promotion of Science (JSPS) Research

4 Fellowships for Young Scientists. This work was supported in part by Grants-in-Aid for

5 Scientific Research 23570067 and 26440159 (YK) from the Ministry of Education, Culture,

6 Sports, Science and Technology of Japan.

\section{References}

91 Lu, N. Z., Wardell, S. E., Burnstein, K. L., Defranco, D., Fuller, P. J., Giguere,

10 V., Hochberg, R. B., McKay, L., Renoir, J. M., Weigel, N. L., Wilson, E. M., McDonnell,

11 D. P. and Cidlowski, J. A. (2006) International Union of Pharmacology. LXV. The

12 pharmacology and classification of the nuclear receptor superfamily: glucocorticoid,

13 mineralocorticoid, progesterone, and androgen receptors. Pharmacological reviews. 58,

$14 \quad 782-797$

152 Markov, G. V., Tavares, R., Dauphin-Villemant, C., Demeneix, B. A., Baker,

16 M. E. and Laudet, V. (2009) Independent elaboration of steroid hormone signaling

17 pathways in metazoans. Proc Natl Acad Sci U S A. 106, 11913-11918

183 Bridgham, J. T., Eick, G. N., Larroux, C., Deshpande, K., Harms, M. J.,

19 Gauthier, M. E., Ortlund, E. A., Degnan, B. M. and Thornton, J. W. (2010) Protein

20 evolution by molecular tinkering: diversification of the nuclear receptor superfamily

21 from a ligand-dependent ancestor. PLoS biology. 8

224 Baker, M. E., Funder, J. W. and Kattoula, S. R. (2013) Evolution of hormone

23 selectivity in glucocorticoid and mineralocorticoid receptors. J Steroid Biochem Mol

24 Biol. 137, 57-70

255 Baker, M. E., Nelson, D. R. and Studer, R. A. (2015) Origin of the response to

26 adrenal and sex steroids: Roles of promiscuity and co-evolution of enzymes and steroid

27 receptors. J Steroid Biochem Mol Biol. 151, 12-24

286 Bridgham, J. T., Carroll, S. M. and Thornton, J. W. (2006) Evolution of

29 hormone-receptor complexity by molecular exploitation. Science. 312, 97-101

307 Thornton, J. W. (2001) Evolution of vertebrate steroid receptors from an

31 ancestral estrogen receptor by ligand exploitation and serial genome expansions. Proc

32 Natl Acad Sci U S A. 98, 5671-5676

338 Funder, J. W. (2012) Aldosterone and mineralocorticoid receptors: a personal

34 reflection. Molecular and cellular endocrinology. 350, 146-150

359 Hawkins, U. A., Gomez-Sanchez, E. P., Gomez-Sanchez, C. M. and

36 Gomez-Sanchez, C. E. (2012) The ubiquitous mineralocorticoid receptor: clinical 
1 implications. Curr Hypertens Rep. 14, 573-580

210 Martinerie, L., Munier, M., Le Menuet, D., Meduri, G., Viengchareun, S. and

3 Lombes, M. (2013) The mineralocorticoid signaling pathway throughout development:

4 expression, regulation and pathophysiological implications. Biochimie. 95, 148-157

511 Rossier, B. C., Baker, M. E. and Studer, R. A. (2015) Epithelial sodium

6 transport and its control by aldosterone: the story of our internal environment revisited.

7 Physiological reviews. 95, 297-340

812 Close, D. A., Yun, S. S., McCormick, S. D., Wildbill, A. J. and Li, W. (2010)

9 11-deoxycortisol is a corticosteroid hormone in the lamprey. Proc Natl Acad Sci U S A.

$10 \quad \mathbf{1 0 7}, 13942-13947$

1113 Roberts, B. W., Didier, W., Rai, S., Johnson, N. S., Libants, S., Yun, S. S. and

12 Close, D. A. (2014) Regulation of a putative corticosteroid,

13 17,21-dihydroxypregn-4-ene,3,20-one, in sea lamprey, Petromyzon marinus. Gen Comp

14 Endocrinol. 196, 17-25

1514 Carroll, S. M., Bridgham, J. T. and Thornton, J. W. (2008) Evolution of

16 hormone signaling in elasmobranchs by exploitation of promiscuous receptors.

17 Molecular biology and evolution. 25, 2643-2652

1815 Greenwood, A. K., Butler, P. C., White, R. B., DeMarco, U., Pearce, D. and

19 Fernald, R. D. (2003) Multiple corticosteroid receptors in a teleost fish: distinct

20 sequences, expression patterns, and transcriptional activities. Endocrinology. 144,

$21 \quad 4226-4236$

2216 Sturm, A., Bury, N., Dengreville, L., Fagart, J., Flouriot, G., Rafestin-Oblin, M.

23 E. and Prunet, P. (2005) 11-deoxycorticosterone is a potent agonist of the rainbow trout

24 (Oncorhynchus mykiss) mineralocorticoid receptor. Endocrinology. 146, 47-55

2517 Stolte, E. H., de Mazon, A. F., Leon-Koosterziel, K. M., Jesiak, M., Bury, N.

26 R., Sturm, A., Savelkoul, H. F., van Kemenade, B. M. and Flik, G. (2008) Corticosteroid

27 receptors involved in stress regulation in common carp, Cyprinus carpio. J Endocrinol.

$28 \quad 198,403-417$

2918 Arterbery, A. S., Fergus, D. J., Fogarty, E. A., Mayberry, J., Deitcher, D. L.,

30 Lee Kraus, W. and Bass, A. H. (2011) Evolution of ligand specificity in vertebrate

31 corticosteroid receptors. BMC Evol Biol. 11, 14

3219 Pippal, J. B., Cheung, C. M., Yao, Y. Z., Brennan, F. E. and Fuller, P. J. (2011)

33 Characterization of the zebrafish (Danio rerio) mineralocorticoid receptor. Molecular

34 and cellular endocrinology. 332, 58-66

3520 Jiang, J. Q., Young, G., Kobayashi, T. and Nagahama, Y. (1998) Eel (Anguilla

36 japonica) testis 11 beta-hydroxylase gene is expressed in interrenal tissue and its product 
1 lacks aldosterone synthesizing activity. Molecular and cellular endocrinology. 146,

2 207-211

$321 \quad$ Baker, M. E. (2003) Evolution of glucocorticoid and mineralocorticoid

4 responses: go fish. Endocrinology. 144, 4223-4225

522 Bury, N. R. and Sturm, A. (2007) Evolution of the corticosteroid receptor

6 signalling pathway in fish. Gen Comp Endocrinol. 153, 47-56

$723 \quad$ Baker, M. E., Chandsawangbhuwana, C. and Ollikainen, N. (2007) Structural

8 analysis of the evolution of steroid specificity in the mineralocorticoid and

9 glucocorticoid receptors. BMC Evol Biol. 7, 24

1024 Sakamoto, T., Mori, C., Minami, S., Takahashi, H., Abe, T., Ojima, D., Ogoshi,

11 M. and Sakamoto, H. (2011) Corticosteroids stimulate the amphibious behavior in

12 mudskipper: potential role of mineralocorticoid receptors in teleost fish. Physiol Behav.

$13 \quad \mathbf{1 0 4}, 923-928$

1425 Takahashi, H. and Sakamoto, T. (2013) The role of 'mineralocorticoids' in

15 teleost fish: relative importance of glucocorticoid signaling in the osmoregulation and

16 'central' actions of mineralocorticoid receptor. Gen Comp Endocrinol. 181, 223-228

1726 Milla, S., Wang, N., Mandiki, S. N. and Kestemont, P. (2009) Corticosteroids:

18 Friends or foes of teleost fish reproduction? Comparative biochemistry and physiology.

19 Part A, Molecular \& integrative physiology. 153, 242-251

2027 Geller, D. S., Farhi, A., Pinkerton, N., Fradley, M., Moritz, M., Spitzer, A.,

21 Meinke, G., Tsai, F. T., Sigler, P. B. and Lifton, R. P. (2000) Activating

22 mineralocorticoid receptor mutation in hypertension exacerbated by pregnancy. Science.

23 289, 119-123

2428 Gilmour, K. M. (2005) Mineralocorticoid receptors and hormones: fishing for

25 answers. Endocrinology. 146, 44-46

2629 Prunet, P., Sturm, A. and Milla, S. (2006) Multiple corticosteroid receptors in

27 fish: from old ideas to new concepts. Gen Comp Endocrinol. 147, 17-23

2830 Jaillon, O., Aury, J. M., Brunet, F., Petit, J. L., Stange-Thomann, N., Mauceli,

29 E., Bouneau, L., Fischer, C., Ozouf-Costaz, C., Bernot, A., Nicaud, S., Jaffe, D., Fisher,

30 S., Lutfalla, G., Dossat, C., Segurens, B., Dasilva, C., Salanoubat, M., Levy, M., Boudet,

31 N., Castellano, S., Anthouard, V., Jubin, C., Castelli, V., Katinka, M., Vacherie, B.,

32 Biemont, C., Skalli, Z., Cattolico, L., Poulain, J., De Berardinis, V., Cruaud, C., Duprat,

33 S., Brottier, P., Coutanceau, J. P., Gouzy, J., Parra, G., Lardier, G., Chapple, C.,

34 McKernan, K. J., McEwan, P., Bosak, S., Kellis, M., Volff, J. N., Guigo, R., Zody, M. C.,

35 Mesirov, J., Lindblad-Toh, K., Birren, B., Nusbaum, C., Kahn, D., Robinson-Rechavi,

36 M., Laudet, V., Schachter, V., Quetier, F., Saurin, W., Scarpelli, C., Wincker, P., Lander, 
1 E. S., Weissenbach, J. and Roest Crollius, H. (2004) Genome duplication in the teleost

2 fish Tetraodon nigroviridis reveals the early vertebrate proto-karyotype. Nature. 431,

$3 \quad 946-957$

431 Kasahara, M., Naruse, K., Sasaki, S., Nakatani, Y., Qu, W., Ahsan, B., Yamada,

5 T., Nagayasu, Y., Doi, K., Kasai, Y., Jindo, T., Kobayashi, D., Shimada, A., Toyoda, A.,

6 Kuroki, Y., Fujiyama, A., Sasaki, T., Shimizu, A., Asakawa, S., Shimizu, N., Hashimoto,

7 S., Yang, J., Lee, Y., Matsushima, K., Sugano, S., Sakaizumi, M., Narita, T., Ohishi, K.,

8 Haga, S., Ohta, F., Nomoto, H., Nogata, K., Morishita, T., Endo, T., Shin, I. T., Takeda,

9 H., Morishita, S. and Kohara, Y. (2007) The medaka draft genome and insights into

10 vertebrate genome evolution. Nature. 447, 714-719

1132 Katsu, Y., Kohno, S., Hyodo, S., Ijiri, S., Adachi, S., Hara, A., Guillette, L. J.,

12 Jr. and Iguchi, T. (2008) Molecular cloning, characterization, and evolutionary analysis

13 of estrogen receptors from phylogenetically ancient fish. Endocrinology. 149,

$14 \quad 6300-6310$

1533 Oka, K., Hoang, A., Okada, D., Iguchi, T., Baker, M. E. and Katsu, Y. (2015)

16 Allosteric role of the amino-terminal A/B domain on corticosteroid transactivation of

17 gar and human glucocorticoid receptors. J Steroid Biochem Mol Biol. 154, 112-119

1834 Katsu, Y., Kohno, S., Oka, K. and Baker, M. E. (2016) Evolution of

19 corticosteroid specificity for human, chicken, alligator and frog glucocorticoid receptors.

20 Steroids. 113, 38-45

2135 Rupprecht, R., Reul, J. M., van Steensel, B., Spengler, D., Soder, M., Berning,

22 B., Holsboer, F. and Damm, K. (1993) Pharmacological and functional characterization

23 of human mineralocorticoid and glucocorticoid receptor ligands. Eur J Pharmacol. 247,

$24 \quad 145-154$

2536 Fagart, J., Wurtz, J. M., Souque, A., Hellal-Levy, C., Moras, D. and

26 Rafestin-Oblin, M. E. (1998) Antagonism in the human mineralocorticoid receptor. The

27 EMBO journal. 17, 3317-3325

2837 Bledsoe, R. K., Madauss, K. P., Holt, J. A., Apolito, C. J., Lambert, M. H.,

29 Pearce, K. H., Stanley, T. B., Stewart, E. L., Trump, R. P., Willson, T. M. and Williams,

30 S. P. (2005) A ligand-mediated hydrogen bond network required for the activation of the

31 mineralocorticoid receptor. The Journal of biological chemistry. 280, 31283-31293

3238 Fagart, J., Huyet, J., Pinon, G. M., Rochel, M., Mayer, C. and Rafestin-Oblin,

33 M. E. (2005) Crystal structure of a mutant mineralocorticoid receptor responsible for

34 hypertension. Nature structural \& molecular biology. 12, 554-555

3539 Saitou, N. and Nei, M. (1987) The neighbor-joining method: a new method

36 for reconstructing phylogenetic trees. Molecular biology and evolution. 4, 406-425 
$140 \quad$ Edgar, R. C. (2004) MUSCLE: multiple sequence alignment with high

2 accuracy and high throughput. Nucleic acids research. 32, 1792-1797

341 Felsenstein, J. (1985) Confidence-Limits on Phylogenies - an Approach Using

4 the Bootstrap. Evolution. 39, 783-791

542 Tamura, K., Peterson, D., Peterson, N., Stecher, G., Nei, M. and Kumar, S.

6 (2011) MEGA5: molecular evolutionary genetics analysis using maximum likelihood,

7 evolutionary distance, and maximum parsimony methods. Molecular biology and

8 evolution. $\mathbf{2 8}, 2731-2739$

943 Kadlecova, Z., Nallet, S., Hacker, D. L., Baldi, L., Klok, H. A. and Wurm, F.

10 M. (2012) Poly(ethyleneimine)-mediated large-scale transient gene expression:

11 influence of molecular weight, polydispersity and N-propionyl groups. Macromol

12 Biosci. 12, 628-636

1344 Oka, K., Kohno, S., Urushitani, H., Guillette, L. J., Jr., Ohta, Y., Iguchi, T. and

14 Katsu, Y. (2013) Molecular cloning and characterization of the corticoid receptors from

15 the American alligator. Molecular and cellular endocrinology. 365, 153-161

1645 Joss, J. M. P., Arnoldreed, D. E. and Balment, R. J. (1994) The Steroidogenic

17 Response to Angiotensin-Ii in the Australian Lungfish, Neoceratodus-Forsteri. J Comp

18 Physiol B. 164, 378-382

1946 Inoue, J., Sato, Y., Sinclair, R., Tsukamoto, K. and Nishida, M. (2015) Rapid

20 genome reshaping by multiple-gene loss after whole-genome duplication in teleost fish

21 suggested by mathematical modeling. Proc Natl Acad Sci U S A. 112, 14918-14923

2247 Tokarz, J., Moller, G., de Angelis, M. H. and Adamski, J. (2013) Zebrafish and

23 steroids: what do we know and what do we need to know? J Steroid Biochem Mol Biol.

24 137, 165-173

2548 Funder, J. and Myles, K. (1996) Exclusion of corticosterone from epithelial

26 mineralocorticoid receptors is insufficient for selectivity of aldosterone action: in vivo

27 binding studies. Endocrinology. 137, 5264-5268

2849 Pascual-Le Tallec, L. and Lombes, M. (2005) The mineralocorticoid receptor:

29 a journey exploring its diversity and specificity of action. Mol Endocrinol. 19,

$30 \quad 2211-2221$

$3150 \quad$ Fuller, P. J., Yao, Y., Yang, J. and Young, M. J. (2012) Mechanisms of ligand

32 specificity of the mineralocorticoid receptor. J Endocrinol. 213, 15-24

$3351 \quad$ Odermatt, A. and Kratschmar, D. V. (2012) Tissue-specific modulation of

34 mineralocorticoid receptor function by 11 beta-hydroxysteroid dehydrogenases: an

35 overview. Molecular and cellular endocrinology. 350, 168-186

3652 Chapman, K., Holmes, M. and Seckl, J. (2013) 11beta-hydroxysteroid 
1 dehydrogenases: intracellular gate-keepers of tissue glucocorticoid action. Physiological

2 reviews. 93, 1139-1206

353 Sivukhina, E. V. and Jirikowski, G. F. (2014) Adrenal steroids in the brain:

4 role of the intrinsic expression of corticosteroid-binding globulin (CBG) in the stress

5 response. Steroids. 81, 70-73

$654 \quad$ Kusakabe, M., Nakamura, I. and Young, G. (2003) 11beta-hydroxysteroid

7 dehydrogenase complementary deoxyribonucleic acid in rainbow trout: cloning, sites of

8 expression, and seasonal changes in gonads. Endocrinology. 144, 2534-2545

955 Baker, M. E. (2010) 11Beta-hydroxysteroid dehydrogenase-type 2 evolved

10 from an ancestral 17beta-hydroxysteroid dehydrogenase-type 2. Biochemical and

11 biophysical research communications. 399, 215-220

$1256 \quad$ Nebert, D. W. and Russell, D. W. (2002) Clinical importance of the

13 cytochromes P450. Lancet. 360, 1155-1162

1457 Payne, A. H. and Hales, D. B. (2004) Overview of steroidogenic enzymes in

15 the pathway from cholesterol to active steroid hormones. Endocr Rev. 25, 947-970

1658 Taves, M. D., Plumb, A. W., Sandkam, B. A., Ma, C., Van Der Gugten, J. G.,

17 Holmes, D. T., Close, D. A., Abraham, N. and Soma, K. K. (2015) Steroid profiling

18 reveals widespread local regulation of glucocorticoid levels during mouse development.

19 Endocrinology. 156, 511-522

$2059 \quad$ Breuner, C. W. and Orchinik, M. (2002) Plasma binding proteins as mediators

21 of corticosteroid action in vertebrates. J Endocrinol. 175, 99-112

2260 Bledsoe, R. K., Montana, V. G., Stanley, T. B., Delves, C. J., Apolito, C. J.,

23 McKee, D. D., Consler, T. G., Parks, D. J., Stewart, E. L., Willson, T. M., Lambert, M.

24 H., Moore, J. T., Pearce, K. H. and Xu, H. E. (2002) Crystal structure of the

25 glucocorticoid receptor ligand binding domain reveals a novel mode of receptor

26 dimerization and coactivator recognition. Cell. 110, 93-105

2761 Li, Y., Suino, K., Daugherty, J. and Xu, H. E. (2005) Structural and

28 biochemical mechanisms for the specificity of hormone binding and coactivator

29 assembly by mineralocorticoid receptor. Mol Cell. 19, 367-380

3062 Hultman, M. L., Krasnoperova, N. V., Li, S., Du, S., Xia, C., Dietz, J. D., Lala,

31 D. S., Welsch, D. J. and Hu, X. (2005) The ligand-dependent interaction of

32 mineralocorticoid receptor with coactivator and corepressor peptides suggests multiple

33 activation mechanisms. Mol Endocrinol. 19, 1460-1473

3463 Khan, S. H., Awasthi, S., Guo, C., Goswami, D., Ling, J., Griffin, P. R.,

35 Simons, S. S., Jr. and Kumar, R. (2012) Binding of the N-terminal region of coactivator

36 TIF2 to the intrinsically disordered AF1 domain of the glucocorticoid receptor is 
1 accompanied by conformational reorganizations. The Journal of biological chemistry.

$2 \quad 287,44546-44560$

364 Fuller, P. J. (2015) Novel interactions of the mineralocorticoid receptor.

4 Molecular and cellular endocrinology. 408, 33-37

565 Pippal, J. B., Yao, Y., Rogerson, F. M. and Fuller, P. J. (2009) Structural and

6 functional characterization of the interdomain interaction in the mineralocorticoid

7 receptor. Mol Endocrinol. 23, 1360-1370

866 Bhargava, A. and Pearce, D. (2004) Mechanisms of mineralocorticoid action:

9 determinants of receptor specificity and actions of regulated gene products. Trends

10 Endocrinol Metab. 15, 147-153

$1167 \quad$ Faresse, N. (2014) Post-translational modifications of the mineralocorticoid

12 receptor: How to dress the receptor according to the circumstances? J Steroid Biochem

13 Mol Biol. 143, 334-342 